\title{
Expression of the SERPING1 gene is not regulated by promoter hypermethylation in peripheral blood mononuclear cells from patients with hereditary angioedema due to $\mathrm{C} 1$-inhibitor deficiency
}

\author{
Alberto López-Lera ${ }^{1,2}$, Olga Pernia ${ }^{3,4}$, Margarita López-Trascasa ${ }^{1,2^{*}}$ and Inmaculada Ibanez de Caceres ${ }^{3,4}$
}

\begin{abstract}
SERPING1 mutations causing Hereditary Angioedema type I (HAE-I) due to C1-Inhibitor (C1-INH) deficiency display a dominant-negative effect usually resulting in protein levels far below the expected $50 \%$. To further investigate mechanisms for its reduced expression, we analyzed the promoter DNA methylation status of SERPING1 and its influence on C1-INH expression. Global epigenetic reactivation correlated with C1-INH mRNA synthesis and protein secretion in Huh7 hepatoma cells. However, PBMCs extracted from controls, HAE-I and HAE-II patients presented identical methylation status of the SERPING1 promoter when analyzed by bisulphite sequencing; the proximal CpG island (exon 2) is constitutively unmethylated, while the most distant one $(5.7 \mathrm{~Kb}$ upstream the transcriptional start site) is fully methylated. These results correlate with the methylation profile observed in Huh7 cells and indicate that there is not a direct epigenetic regulation of C1-INH expression in PBMCs specific for each HAE type. Other indirect modes of epigenetic regulation cannot be excluded.
\end{abstract}

Keywords: Promoter DNA methylation, C1-INH protein, SERPING1 gene, Hereditary Angioedema, PBMCs (Peripheral Blood Mononuclear Cells)

\section{Background}

C1-Inhibitor (C1-INH; OMIM\#606860) is a SERPIN regulating the activation of the classical and lectin complement pathways, coagulation and fibrinolysis cascades [1]. It is mainly produced in the liver, although local synthesis by monocytes, fibroblasts and endothelial cells in inflammatory foci also exists. Deficiency of C1-INH due to mutations in the SERPING1 gene causes Hereditary Angioedema (HAE) types I and II. HAE type I (HAE-I) can be due to mutations located throughout the gene sequence and is characterized by functional and antigenic C1-INH deficiency. HAE type II (HAE-II) is caused by point mutations

\footnotetext{
*Correspondence: mltrascasa@salud.madrid.org

'Immunology Unit and IdIPAZ, University Hospital La Paz, Paseo Castellana 261, Madrid 28046, Spain

${ }^{2}$ Unit 754, Centre for Biomedical Research on Rare Diseases (CIBERER), Madrid, Spain

Full list of author information is available at the end of the article
}

affecting the reactive centre of the protein or nearby residues and presents with reduced function but normal antigenic levels of the protein. HAE patients suffer from recurrent disabling episodes of swelling in the subcutaneous and submucosal layers which can affect any body location and, if not promptly and properly treated, can lead to suffocation when the larynx is affected [2].

HAE is inherited in an autosomal dominant manner. Typically, HAE-I heterozygous patients exhibit C1-INH levels that are markedly below the expected $50 \%$ of controls, while type II patients have normal levels, but reduced function of C1-INH. Thus, regarding protein levels, HAE-I mutant alleles seem to exert dominant negative effects on their wild-type counterparts, rendering similarly reduced mRNA levels in both alleles to around 50\% [3-5]. Additionally, a small percentage of HAE patients exhibiting reduced C1-INH function do not carry known SERPING1 
mutations even after exhaustive sequence analyses and MLPA screening; therefore, alternative modes of regulating C1-INH remain to be identified.

DNA methylation is an epigenetic event that plays a role in development, aging, chromatin structure, genomic imprinting and gene and microRNA expression. Altered DNA methylation patterns have been described in many genes and microRNAs associated with disease [6-8], including some members of the SERPIN superfamily, whose epigenetic alterations have been described in human placental diseases [9]. To contribute to the understanding of C1-INH's regulation of expression in $\mathrm{HAE}$, we have investigated the CpG methylation status of the C1-INH locus and its surrounding regions in the hepatoma cell line Huh7 and in stored DNA samples from PBMCs obtained from healthy donors, HAE-I and HAE-II patients.

\section{Results and disussion}

Identification of putative CpG islands in the SERPING1 locus The screening for $\mathrm{CpG}$ islands was initially performed in the SERPING1's genomic region containing its coding sequences (exons 1 to 8 and their adjacent introns). Next, we extended the search $6 \mathrm{~kb}$ in 5 ' direction until the closest $\mathrm{CpG}$ cluster addressing the selection criteria:

More than 55\% of GC dinucleotides (i), ObservedCpG vs. Expected CpG ratio: 0.65 (ii), Length: at least $200 \mathrm{bp}$ (iii), Distance: 100 bp (iv).

Two relaxed CpG islands endorsed by literature [9] were identified in the 11q11-q13.1 region according to the CpG Island Searcher software (http://cpgislands.usc.edu/) [10] (Figure 1A). The nearest CpG island to the ATG site (referred to as CpG island 1 or 3 ' island) comprises the 73 bp-exon 2 of the SERPING1 gene and its surrounding intronic regions, 58 bp upstream and 224 bp downstream

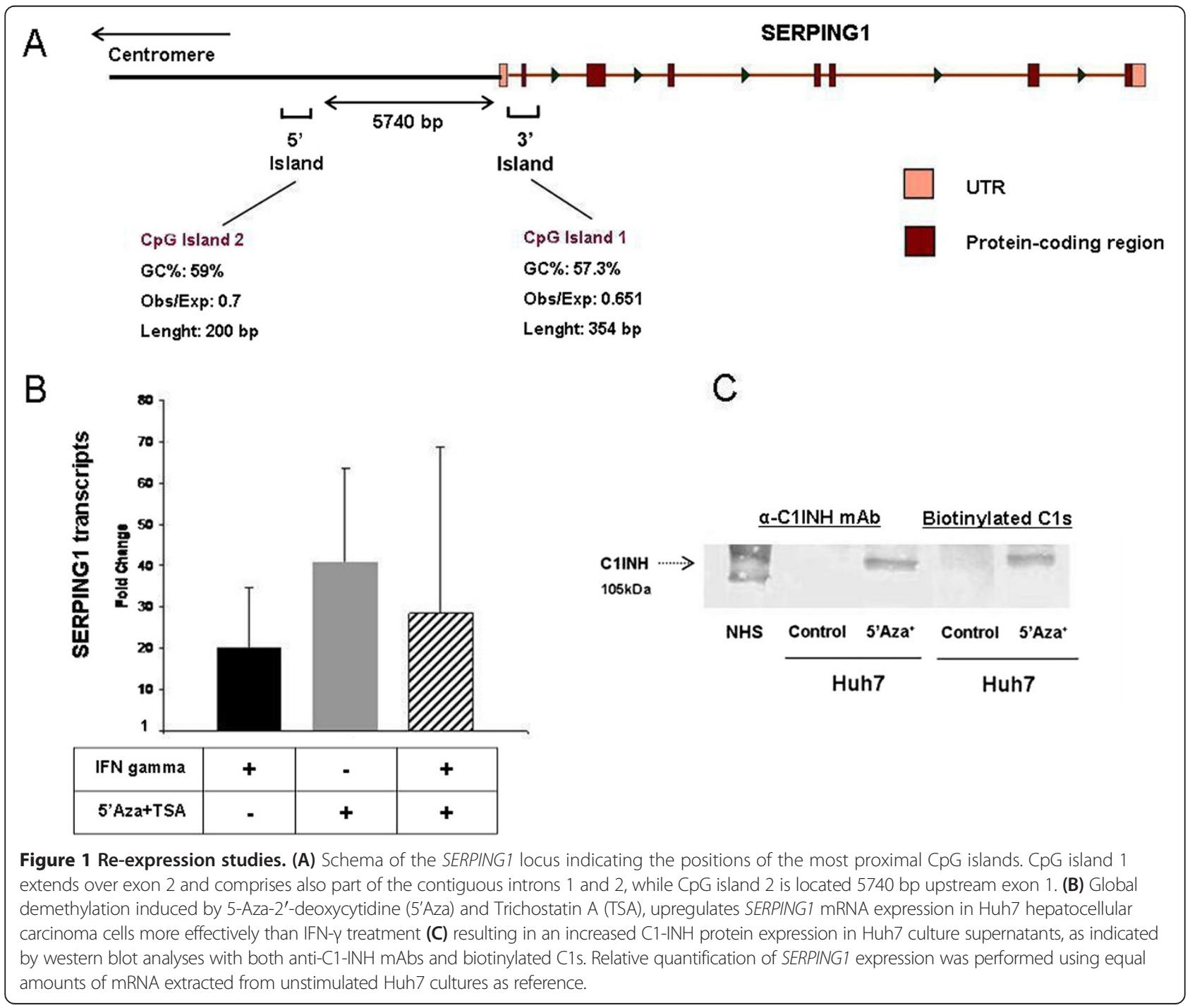


the second exon. It is $354 \mathrm{bp}$ in length and contains $57.3 \%$ of CpG dinucleotides. The second CpG island - termed CpG island 2 or 5 ' island- is located between 5940 and 5740 bp upstream of the gene's first exon. It contains 59\% CpGs and spans $200 \mathrm{bp}$.

\section{Global demethylation induced by 5'Aza and TSA upregulates SERPING1 expression in Huh7 cells at the mRNA and protein levels}

To our knowledge, no studies focused on quantifying C1-INH synthesis in Huh7 cells have been published, but the matter has been extensively addressed in other hepatocellular carcinoma cell lines, especially in the HepG2 line. HepG2 cells synthesize and secrete functional C1INH and its expression is enhanced by IFN- $\gamma$ administration in a dose-dependent manner [11,12].

We quantified C1-INH mRNA from $1 \mu \mathrm{g}$ of total RNA extracted from $75 \%$ confluent Huh-7 control cell cultures and compared it to that of Huh7 cells treated with 5 'Aza + TSA for 3 culture days as described [13]. Reversetranscription with oligo-dT primers (Qiagen, Valencia, CA) and quantification using a SYBR Green system (Applied Biosystems, Foster City, CA) were performed as previously described [14].

Similarly to what is seen in IFN- $\gamma$ treated cells, global demethylation strongly correlated with enhanced SERPING1 mRNA synthesis. Furthermore, mRNA synthesis was higher in 5'Aza + TSA-treated cultures (38-fold) than in those exposed to $250 \mathrm{UI} / \mathrm{mL}$ of IFN- $\gamma$ for 3 days (20-fold). Combined addition of 5Aza, TSA and IFN- $\gamma$ during 3 culture days produced a non-additive effect resulting in a 28-fold change upregulation of SERPING1 expression (Figure 1B). This probably reflects the consequences of global DNA/histones demethylation on the transcriptional/ translational regulation of the IFNG gene (encoding human IFN- $\gamma$ ) or other loci involved in the transduction of IFN- $\gamma$

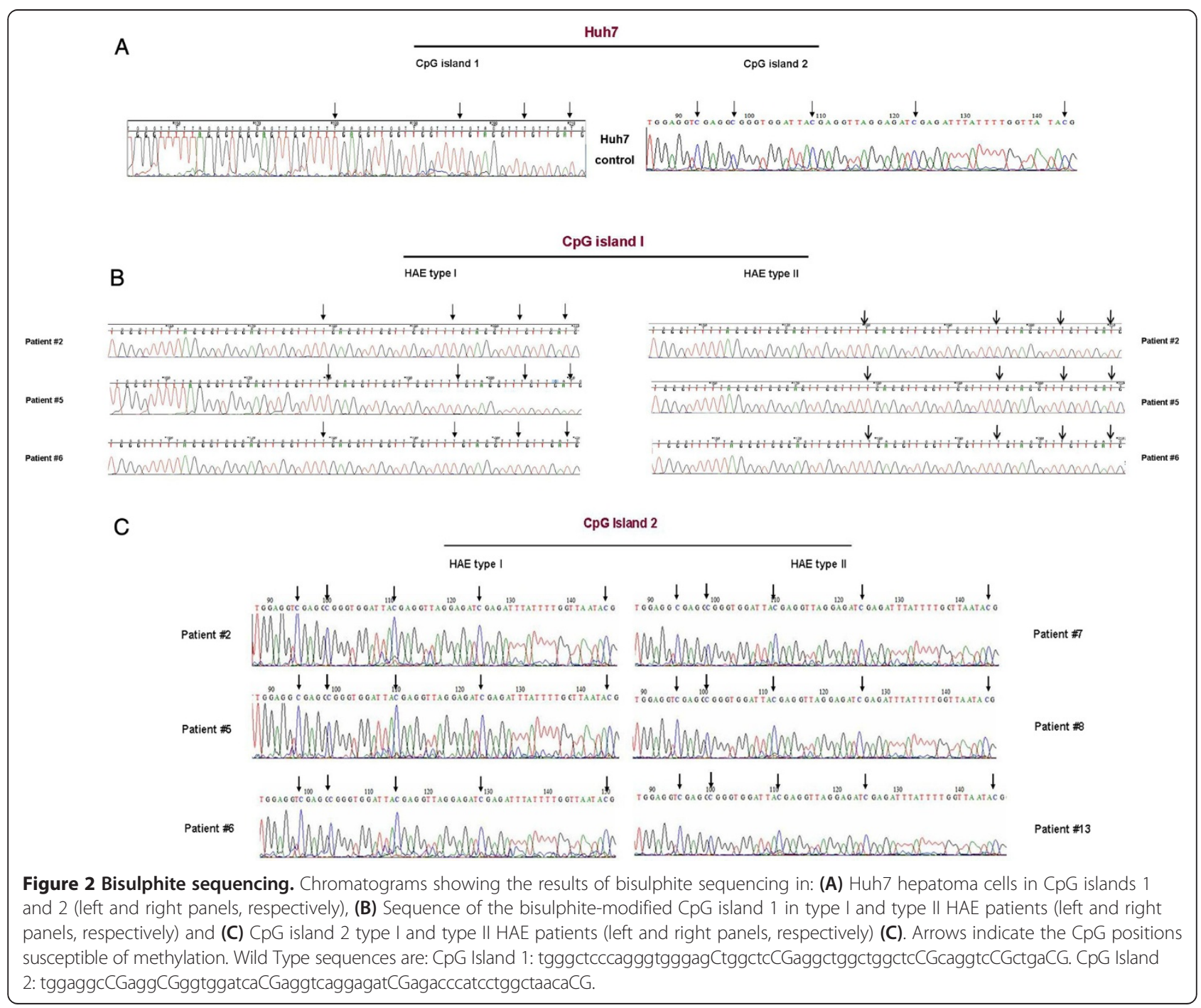


signalling. In fact, DNA and histones' epigenetic marks are known to play a role in transcriptional activation and silencing of IFN- $\gamma$ signalling [15].

C1-INH protein presents two different isoforms in serum and plasma by western blot analysis: a $105 \mathrm{KDa}$ protein representing its native, non-cleaved conformation and an additional $96 \mathrm{kDa}$ form corresponding to its cleaved, latent, non-functional conformation. In our hands, Huh7 cultures exhibit a single $105 \mathrm{kDa}$ native band, which suggests the absence of activity involving those serum proteolytic pathways regulated by $\mathrm{C} 1-\mathrm{INH}$ (Figure 1C). Western blot analysis of culture supernatants confirmed SERPING1 synthesis observed at the RNA level; no bands were observed in the supernatants of control Huh7 cells after three days of culture, while a single $105 \mathrm{kDa}$ band corresponding to the native conformation of C1-INH was visible in treated Huh7 cells both by monoclonal anti-C1-INH antibody and biotinylated-C1s' detection systems (Figure 1C). Those results indicate a possible epigenetic regulation of SERPING1 gene expression in the Huh7 hepatoma cells.

\section{CpG island 1 is unmethylated in HAE patients and controls while $\mathrm{CpG}$ island 2 is methylated}

Bisulphite sequencing of stored genomic DNA samples obtained from HAE PBMCs (8 type I and 8 type II, Additional file 1), 10 healthy donor PBMCs and Huh7 cells was carried out as previously described [16] These studies received approval from the ethical committee of Hospital La Paz.

We included genomic DNAs from a homozygousdeficient patient carrying the R378C missense mutation in exon 7 and a heterozygous relative (samples 3 and 3b, respectively). Genetic and biochemical characterization of these patients has been previously described [17]. The T157fsX78 frameshift mutation in HAE-I patients 4, 4b and $4 \mathrm{c}$ and the exon 4 deletion in patients 1 and 6 are expected to profoundly reduce SERPING1 mRNA levels due to the introduction of premature stop codons. In contrast, the remaining type I and type II mutations do not have obvious implications on translation or protein structure.

Sequencing results showed that in all cases the proximal CpG island 1 is unmethylated while the distal CpG island 2 is fully methylated (Figure 2). There is no difference between Huh7 cells, control PBMCs and those obtained from either HAE-I or HAE-II patients regarding the methylation status of both $\mathrm{CpG}$ islands 1 and 2 analyzed in this manuscript, indicating that there is no direct epigenetic regulation at DNA level. Therefore, transcriptional regulation of the SERPING1 gene in pathological situations like HAE is not dependent on the methylation status of the analysed CpG islands. This epigenetic pattern is in agreement with that reported by Chelbi and collaborators in normal and preeclampsic placentas [9] and it is also concordant with repository data on DNase-I treatment and transcription factor binding site accessibility in the region, which shows a peak for DNaseI sensitivity centred in SERPING1's exon 2 that matches CpG island 1 [18].

Considering the lack of evidence for differential epigenetic regulation at the DNA methylation level of promoter activity in the SERPING1 locus in HAE patients' PBMCs, the fact that the demethylating agents 5 'Aza-dC and TSA strongly increased mRNA and protein synthesis in Huh7 cells could reflect an upstream indirect epigenetic regulation of trans-acting factors like transcription factors or microRNAs in the hepatocyte. Those elements could be reactivated by demethylation as has been reported in previous studies using similar experimental epigenetic reactivation approaches $[13,19]$. On the other hand, we found no evidence for epigenetic mechanisms involving promoter CpG islands 1 and 2 playing a starring role in the negative dominance previously reported in HAE-I PBMCs.

The approach employed in this paper for the analysis of SERPING1 epigenetics is evidently hindered by the impossibility of obtaining hepatocyte samples from patients and controls in which to perform re-expression studies and bisulphite sequencing. Moreover, taking into consideration that monocytes do not undergo cell division, they are not suitable for 5'AZA + TSA re-expression studies, as a minimum of two cell divisions are required to completely remove epigenetic marks from DNA and histones. Therefore, these results are strictly limited to PBMCs and do not inform about epigenetic regulation in the hepatocyte, which is the main source of plasma C1-INH.

All considered, our data suggest that $\mathrm{CpG}$ island 1 is in a transcriptional-permissive chromatin conformation that would hypothetically allow the access of transcriptional machinery to the gene's promoter sites in PBMCs. The upregulating effect of demethylating agents on Huh7 cells would be due to epigenetic regulation of additional factors involved in SERPING1's control of transcription and suggests an analogous mechanism could account for the differential C1-INH plasma levels characteristic of each HAE type.

\section{Additional file}

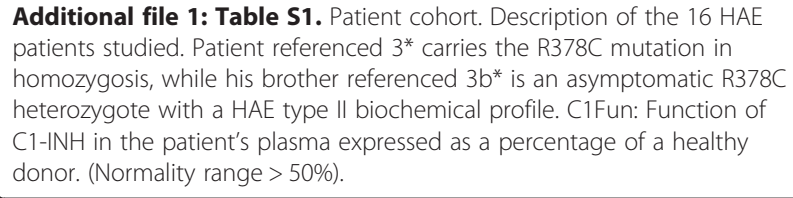

Additional file 1: Table S1. Patient cohort. Description of the $16 \mathrm{HAE}$ patients studied. Patient referenced $3^{*}$ carries the R378C mutation in homozygosis, while his brother referenced $3 b^{*}$ is an asymptomatic R378C heterozygote with a HAE type II biochemical profile. C1Fun: Function of C1-INH in the patient's plasma expressed as a percentage of a healthy donor. (Normality range $>50 \%$ ).

Competing interests

The authors declare that they have no competing interests. 


\section{Authors' information}

López-Trascasa Margarita and Ibanez de Caceres Inmaculada are Senior authors.

\section{Acknowledgements}

We are thankful to the patients, their families and clinicians for being part of these studies.

\section{Funding}

The work was funded by grants PS09/00122 by Instituto de Salud Carlos III (ISCIII) and Ministerio de Economía y Competitividad SAF2012-38636. OP and IIC were supported by FIS PS09/00472, PI12/00386 and Miguel Servet (CP 08/000689; PI-717). ALL was supported by CIBERER (Instituto de Salud Carlos III, ISCIII) and co-financed with FEDER funds.

\section{Author details}

'Immunology Unit and IdIPAZ, University Hospital La Paz, Paseo Castellana 261, Madrid 28046, Spain. ${ }^{2}$ Unit 754, Centre for Biomedical Research on Rare Diseases (CIBERER), Madrid, Spain. ${ }^{3}$ Cancer Epigenetics Laboratory, INGEMM, University Hospital La Paz, Madrid, Spain. ${ }^{4}$ Biomarkers and Experimental Therapeutics in Cancer, IdiPAZ, Madrid, Spain.

Received: 24 February 2014 Accepted: 27 June 2014

Published online: 22 July 2014

\section{References}

1. Bowen T, Cicardi M, Farkas H, Bork K, Longhurst HJ, Zuraw B, Aygoeren-Pürsün E, Craig T, Binkley K, Hebert J, Ritchie B, Bouillet L, Betschel S, Cogar D, Dean J, Devaraj R, Hamed A, Kamra P, Keith PK, Lacuesta G, Leith E, Lyons H, Mace S, Mako B, Neurath D, Poon MC, Rivard GE, Schellenberg R, Rowan D, Rowe A, et al: 2010 International consensus algorithm for the diagnosis, therapy and management of hereditary angioedema. Allergy Asthma Clin Immunol 2010, 6(1):24. doi:10.1186/1710-1492-6-24.

2. Caballero T, Farkas H, Bouillet L, Bowen T, Gompel A, Fagerberg C, Björkander J, Bork K, Bygum A, Cicardi M, de Carolis C, Frank M, Gooi JH, Longhurst H, Martínez-Saguer I, Nielsen EW, Obtulowitz K, Perricone R, Prior N, C-1-INH Deficiency Working Group: International consensus and practical guidelines on the gynecologic and obstetric management of female patients with hereditary angioedema caused by $\mathrm{C} 1$ inhibitor deficiency. J Allergy Clin Immunol 2012, 129(2):308-320.

3. Kramer J, Rosen FS, Colten HR, Rajczy K, Strunk RC: Transinhibition of C1 inhibitor synthesis in type I hereditary angioneurotic edema. J Clin Invest 1993, 91(3):1258-1262.

4. Pappalardo E, Zingale LC, Cicardi M: C1 inhibitor gene expression in patients with hereditary angioedema: quantitative evaluation by means of real-time RT-PCR. J Allergy Clin Immunol 2004, 114(3):638-644.

5. Cugno M, Zanichelli A, Foieni F, Caccia S, Cicardi M: C1-inhibitor deficiency and angioedema: molecular mechanisms and clinical progress. Trends $\mathrm{Mol}$ Med 2009, 15(2):69-78. doi:10.1016/.j.molmed.2008.12.001.

6. Feinberg AP: Phenotypic plasticity and the epigenetics of human disease. Nature 2007, 447(7143):433-440.

7. Toyota M, Suzuki H, Sasaki Y, Maruyama R, Imai K, Shinomura Y, Tokino T: Epigenetic silencing of microRNA-34b/c and B-cell translocation gene 4 is associated with CpG island methylation in colorectal cancer. Cancer Res 2008, 68:4123-4132.

8. Grady WM, Parkin RK, Mitchell PS, Lee JH, Kim YH, Tsuchiya KD, Washington MK, Paraskeva C, Willson JK, Kaz AM, Kroh EM, Allen A, Fritz BR, Markowitz SD, Tewari M: Epigenetic silencing of the intronic microRNA hsa-miR-342 and its host gene EVL in colorectal cancer. Oncogene 2008, 27:3880-3888.

9. Chelbi ST, Mondon F, Jammes H, Buffat C, Mignot TM, Tost J, Busato F, Gut I, Rebourcet R, Laissue P, Tsatsaris V, Goffinet F, Rigourd V, Carbonne B, Ferré F, Vaiman D: Expressional and epigenetic alterations of placental serine protease inhibitors: SERPINA3 is a potential marker of preeclampsia. Hypertension 2007, 49(1):76-83. Epub 2006 Nov 6.

10. Takai $D$, Jones PA: The CpG island searcher: a new WWW resource. In Silico Biol 2003, 3(3):235-240

11. Lappin DF, Guc D, Hill A, MCShane T, Whaley K: Effect of interferon-gamma on complement gene expression in different cell types. Biochem J 1992, 281(Pt 2):437-442.
12. Morris KM, Aden DP, Knowles BB, Colten HR: Complement biosynthesis by the human hepatoma-derived cell line HepG2. J Clin Invest 1982, 70(4):906-913.

13. Ibanez de Caceres I, Dulaimi E, Hoffman AM, Al-Saleem T, Uzzo RG, Cairns P: Identification of novel target genes by an epigenetic reactivation screen of renal cancer. Cancer Res 2006, 66(10):5021-5028.

14. de la Cruz RM, López-Lera A, López-Trascasa M: Analysis of SERPING1 expression on hereditary angioedema patients: quantitative analysis of full-length and exon 3 splicing variants. Immunol Lett 2012, 141(2):158-164. doi:10.1016/j.imlet.2011.07.011.

15. Aune TM, Collins PL, Collier SP, Henderson MA, Chang S: Epigenetic Activation and Silencing of the Gene that Encodes IFN- - . Front Immunol 2013, 4:112. doi:10.3389/fimmu.2013.00112.

16. Ibanez de Caceres I, Cortes-Sempere M, Moratilla C, Machado-Pinilla R, Rodriguez-Fanjul V, Manguán-García C, Cejas P, López-Ríos F, Paz-Ares L, de CastroCarpeño J, Nistal M, Belda-Iniesta C, Perona R: IGFBP-3 hypermethylation-derived deficiency mediates cisplatin resistance in non-small-cell lung cancer. Oncogene 2010, 29(11):1681-1690. doi:10.1038/onc.2009.454.

17. López-Lera A, Favier B, de la Cruz RM, Garrido S, Drouet C, López-Trascasa $\mathrm{M}$ : A new case of homozygous $\mathrm{C} 1$-inhibitor deficiency suggests a role for Arg378 in the control of kinin pathway activation. J Allergy Clin Immunol 2010, 126(6):1307-10.e3. doi:10.1016/j.jaci.2010.07.037.

18. Flicek $\mathrm{P}$, Amode MR, Barrell D, Beal K, Billis K, Brent $\mathrm{S}$, Carvalho-Silva $\mathrm{D}$, Clapham P, Coates G, Fitzgerald S, Gil L, Girón CG, Gordon L, Hourlier T, Hunt $\mathrm{S}$, Johnson N, Juettemann $T$, Kähäri AK, Keenan $S$, Kulesha $E$, Martin FJ, Maurel T, McLaren WM, Murphy DN, Nag R, Overduin B, Pignatelli M, Pritchard B, Pritchard E, Riat HS, et al: Ensembl 2014. Nucleic Acids Res 2014, (Database issue):D749-D755. doi:10.1093/nar/ gkt1196.

19. Agathanggelou A, Bièche I, Ahmed-Choudhury J, Nicke B, Dammann R, Baksh S, Gao B, Minna JD, Downward J, Maher ER, Latif F: Identification of novel gene expression targets for the Ras association domain family 1 (RASSF1A) tumor suppressor gene in non-small cell lung cancer and neuroblastoma. Cancer Res 2003, 63(17):5344-5351.

\section{doi:10.1186/s13023-014-0103-y}

Cite this article as: López-Lera et al:: Expression of the SERPING1 gene is not regulated by promoter hypermethylation in peripheral blood mononuclear cells from patients with hereditary angioedema due to C1-inhibitor deficiency. Orphanet Journal of Rare Diseases 2014 9:103.

\section{Submit your next manuscript to BioMed Central and take full advantage of:}

- Convenient online submission

- Thorough peer review

- No space constraints or color figure charges

- Immediate publication on acceptance

- Inclusion in PubMed, CAS, Scopus and Google Scholar

- Research which is freely available for redistribution

Submit your manuscript at www.biomedcentral.com/submit
C Biomed Central 